\title{
자 료
}

\section{영양사의 직무능력 향상을 위한 계속교육의 참여동기 분석}

\author{
손정민 ${ }^{1}$ 조영연 ${ }^{2} \cdot$ 배미용 $^{3} \cdot$ 도은경 ${ }^{3} \cdot$ 나우리 $^{1} \cdot$ 김미성 $^{1 \dagger}$ \\ ${ }^{1}$ 원광대학교 식품영양학과 $\cdot{ }^{2}$ 삼성서울병원 임상영양팀 ${ }^{3}$ 대한영양사협회 교육국
}

\author{
Analysis of Reasons for Continuing Education in Dietitians \\ Cheong - Min Sohn ${ }^{1} \cdot$ Young - Yun $\mathrm{Cho}^{2} \cdot \mathrm{Mi}-$ Yong $\mathrm{Bea}^{3} \cdot$ Eun - Kyoung $\mathrm{Do}^{3}$ \\ Woo- $\mathrm{Ri} \mathrm{Na}{ }^{1} \cdot \mathrm{Mi}-$ Sung $\mathrm{Kim}^{1+}$ \\ ${ }^{I}$ Dept. of Food \& Nutrition, Wonkwang University, Iksan, Jeonbuk 570-749, Korea \\ ${ }^{2}$ Dept. of Dietetics, Samsung Medical Center, Seoul 135-710, Korea \\ ${ }^{3}$ Dept. of Educational, The Korean Dietetic Association, Seoul 156-860, Korea
}

\begin{abstract}
This study analyzed the reasons for continuing education among dietitians. An internet-based survey of 622 dieticians was conducted from August 31, 2012 to September 12, 2012. Based on data from the Participation Reasons Scale (PRS) questionnaire, factor analysis was conducted by principle component analysis for the extraction of major factors. Subsequent reliability analysis was performed by assessing Cronbach's $\alpha$. The ANOVA-test was performed to compare the participation reason scores for each factors according to general characteristics. Statistical analysis was performed using SPSS ver.17.0, and $\mathrm{P}<0.05$ was considered significant. Factor analysis for the participation reasons revealed four types of factors. These factors were "maintenance and development of professional competencies", "interaction and responsibility of professionals", "job stability and personal profits" and "services for customers" respectively. Among the participation reasons, "maintenance and development of professional competencies" was the first reason with a $29.34 \%$ variance. In addition, the participation reasons for continuing education differed according to age $(\mathrm{P}<0.05)$, the highest level of education $(\mathrm{P}<0.05)$, workplace $(\mathrm{P}<0.01)$, and work experience in dietetic area $(\mathrm{P}<0.001)$. In conclusion, continuing education programs for dietitians should focus on effectively developing and promoting professionalism.
\end{abstract}

Key words : dietitian, participation reasons scale, continuing education

\section{서 론}

This paper was supported by grants from The Korean Dietetic Association in 2012.

접수일 : 2013년 6월 14일, 수정일 : 2013년 9월 4일,

채택일 : 2013년 9월 9일

${ }^{\dagger}$ Corresponding author: Mi-Sung Kim, Department of Food and Nutrition, Wonkwang University, $460 \mathrm{lksan}-$ daero, Iksan, Jeonbuk 570-749, Korea

Tel : 82-63-850-6656, Fax : 82-63-850-7301

E-mail : misung@wku.ac.kr

\begin{abstract}
급변하는 사회 환경에서 개인의 경쟁력 강화는 현대인의 필수요소로 자리 잡고 있으며, 이를 위해 개인의 지속적인 직업 능력의 향상이 요구되고 있 다. 특히 현대 사회에서는 보건·의료직의 전문성 역할이 확대되고 있으며, 국민소득의 증가, 인구구
\end{abstract}


조의 변화, 식품산업의 발달, 건강수준과 질병양상 의 변화 등 사회 요인 변화에 맞춘 새로운 직업 능 력 교육이 요구되고 있다(Cervero 2001). 최근 식품 외식산업의 급속한 발전과 식생활의 변화에 따른 질병발생 양상의 변화 등 영양사의 사회적인 역할 변화와 확대가 요구되어 있어 이에 따른 영양사 대 상의 계속교육의 요구가 증가하고 있다. 그러나 2010년 국민영양관리법의 시행으로 2년마다 6시간의 영양사 보수교육을 의무화 하였으나 새로이 변하고 다양해지고 있는 지식정보를 제공하는 데는 시간적 인 한계가 있다.

계속교육이란 전문가들의 지속적인 학습요구에 대한 연구와 실천이라고 정의하고 있으며(Cervero 2001), 협회, 직장, 대학 또는 영리기관 등에서 운영 하는 것으로 영양관리 수준 및 자질 향상을 위하여 법적인 강제성을 가지고 시행하는 영양사 보수교육 과는 차이점이 있다. 타 직종 중 간호사의 계속교육 은 협회주관교육, 직무교육, 학위과정 등이 있으며, 대한간호사협회에서 보수교육은 "간호사의 전문적인 성장과 발전을 위하여 간호실무, 교육, 행정 분야에 서 요구되는 새로운 지식, 기술, 태도를 습득하는 것이다"라고 정의하였으며, 영양사들의 보수교육과 동일하게 법적인 규제를 가지고 시행하고 있다.

계속교육의 효과적 이행을 위한 선행 연구 결과 에 따르면, 참여동기가 가장 크게 교육효과에 영향 을 미치는 요인으로 나타나고 있다(Murphy 등 2006). 참여동기에 관한 연구는 Grotelueschen가 전문 직 종사자의 참여동기 조사 연구를 통해 추출된 주 제에 따라 그룹화 하여 참여동기 척도(Participation Reasons Scale; PRS)를 개발하였으며(Grotelueschen 1985), 이후 판사, 의사, 수의사, 경영자 및 간호사 등을 대상으로 개발된 참여동기 척도에 대한 검증 연구가 시행되었다(DeSilets 1995; Aucoin 1998; Hayajneh 2009). 전문가의 직종에 따라 참여동기 요인 의 순위의 차이는 있으나 대표적 참여동기 요인으 로는 전문성 향상과 개발, 전문적 서비스, 동료 학 습과 상호작용, 전문적 헌신과 성찰, 개인적 이익과
직업안정 등으로 보고되고 있다.

국내에서는 보건·의료직의 계속교육에 대한 연 구는 의사 및 간호사를 대상으로 주로 계속교육의 긍정도, 직무만족도 등의 관계를 살펴보는 연구 및 계속교육의 시스템 구축에 관한 연구는 수행된 바 있으나, 계속교육 대상자의 참여동기에 대한 분석은 매우 미흡한 실정이다(Kang 2004). 일부 간호사의 계속교육 참여동기에 관한 연구 결과에 따르면 참 여동기에 따라 교육 유형의 차이와 개인적 특성의 차이를 보여 계속교육의 유형과 개인적 특성을 반 영한 계속교육의 개발, 운영 및 평가 시행의 필요성 을 제안하고 있으나(Han \& Lee 2010), 국내 영양사 를 대상으로 계속교육의 참여동기에 관한 연구는 현재 이루어진 바 없다.

따라서 본 연구에서는 영양사 직무능력 향상을 위한 계속교육의 참여동기를 분석하여 향후 영양사 의 계속교육 프로그램 개발을 위한 기초자료로 사 용하고자 한다.

\section{연구방법}

\section{1. 조사 대상 및 기간}

본 연구는 2012년 8월 31일부터 2012년 9월 12일 까지 대한영양사협회에 등록되어 있는 협회 회원 1,191 명에게 무작위로 온라인 설문지를 발송하였다. 이 중 623 명이 설문에 응하였으며, 설문지 작성을 미완료한 1명의 회원을 제외한 622 명(99.8\%)을 대상 으로 분석을 실시하였다.

\section{2. 조사내용}

영양사의 직무능력 향상을 위한 계속교육의 참여 동기를 조사하기 위해 Grotelueschen와 간호사들의 참여동기를 분석한 $\mathrm{Han}$ 의 선행연구에서 사용한 30 문항을 수정-보완하였으며 4 문항을 추가하여 총 34 
문항을 조사하였다(Grotelueschen 1985; Han \& Lee 2010). 평가는 리커트 7첨 척도를 사용하여 분석하 였다. 일반적 특성을 파악하기 위해 연령, 경력, 최 종학력, 근무형태 등을 조사하였다.

\section{3. 통계분석}

연구에 참여한 영양사의 일반적인 특성을 파악하 기 위해 빈도분석을 실시하였다. 영양사 계속교육의 참여동기를 알아보기 위해 34 개 문항에 근거하여 직접 관측되지 않은 요인의 추출을 위해 주성분 분 석(PCA; Principle Component Analysis)을 이용한 요 인분석을 실시하여 신뢰도인 Cronbach's $\alpha$ 를 측정 하고 참여동기 요인을 추출하였다. 또한 추출된 참 여동기 요인에 따른 일반적 특성의 차이의 분석을 위해 ANOVA 분석을 실시하였다. 수집된 자료의 통

Table 1. General characteristics of subjects.

\begin{tabular}{|c|c|c|c|}
\hline \multicolumn{2}{|c|}{ Variables } & $\begin{array}{c}\text { Frequency } \\
(\mathrm{N})\end{array}$ & $\begin{array}{c}\text { Percentage } \\
(\%)\end{array}$ \\
\hline \multirow{4}{*}{ Age } & $\leq 29$ & 92 & 14.8 \\
\hline & $30 \sim 39$ & 209 & 33.6 \\
\hline & $40 \sim 49$ & 262 & 42.1 \\
\hline & $\geq 50$ & 59 & 9.5 \\
\hline \multirow{4}{*}{$\begin{array}{l}\text { The highest level of } \\
\text { education }\end{array}$} & College graduation & 70 & 11.3 \\
\hline & University graduation & 322 & 51.8 \\
\hline & Master degree & 203 & 32.6 \\
\hline & Doctoral degree & 27 & 4.3 \\
\hline \multirow{5}{*}{ Workplace } & Hospitals & 200 & 32.2 \\
\hline & Schools & 251 & 40.4 \\
\hline & Industries & 46 & 7.4 \\
\hline & $\begin{array}{l}\text { Public health centers } \\
\text { or welfare facilities }\end{array}$ & 48 & 7.7 \\
\hline & $\begin{array}{l}\text { Kindergartens, child } \\
\text { carecenter etc. }\end{array}$ & 77 & 12.4 \\
\hline \multirow{5}{*}{$\begin{array}{l}\text { Work experience in } \\
\text { dietetic area (years) }\end{array}$} & $<1$ & 94 & 15.1 \\
\hline & $1 \sim 3$ & 86 & 13.8 \\
\hline & $4 \sim 6$ & 106 & 17.0 \\
\hline & $7 \sim 10$ & 228 & 36.7 \\
\hline & $>10$ & 108 & 17.4 \\
\hline \multicolumn{2}{|l|}{ Total } & 622 & 100.0 \\
\hline
\end{tabular}

계처리는 SPSS v. 17.0 을 활용하였으며, 유의 수준은 $\mathrm{P}<0.05$ 로 하였다.

\section{결 과}

\section{1. 대상자의 일반적 특성}

본 연구에 참여한 영양사의 일반적 특성은 Table 1 과 같다. 참여대상자는 30 세 미만이 92 명(14.8\%), 30 대 209명(33.6\%), 40대 262명(42.1\%), 50대 이상 59 명(9.5\%)으로 나타났다. 참여대상자의 최종학력은 전 문대학 졸업 70 명 $(11.3 \%)$, 4년제 대학 졸업 322명 $(51.8 \%)$, 석사 졸업 203 명 $(32.6 \%)$, 박사 졸업 27명 (4.3\%)으로 나타났다. 참여대상자의 근무처는 학교가 251 명(40.4\%), 병원 200명(32.2\%), 유치원, 어린이집 등의 기타 77 명 $(12.4 \%)$, 보건쇠사회복지시설 48 명 (7.7\%), 산업체 46명 $7.4 \%)$ 순으로 나타났다. 참여대 상자의 영양사 업무 근무경력은 1년 미만 94 명 (15.1\%), 1 3년 86명(13.8\%), 4 6년 106명(17.0\%), 7 10년 228명(36.7\%), 10년 이상 108명(17.4\%)으로 나타났다.

\section{2. 전문영양사 계속교육 참여동기에 대한 타당성 및 신뢰도 검증}

전문영양사 계속교육 참여동기에 대한 타당성 및 신뢰도 검정을 위해 요인분석을 실시한 결과는 Table 2 와 같다. 총 4 개의 요인이 도출되었고, 각 요 인을 구성하는 문항들의 중심개념을 바탕으로 요인 명을 부여하여 요인 1(29.343\%)은 '전문역량 유지 및 개발', 요인 2(17.307\%) '상호교류 및 전문가의 책임', 요인 3(12.290\%) '직업의 안정성, 개인의 이 익', 요인 4(12.168\%)는 '고객에 대한 서비스'로 명명 하였다. 이 중 '전문역량 유지 및 개발'의 설명 분산 이 $29.343 \%$ 로 가장 컸으며, 4 개 요인을 통해 전체 분산의 $71.108 \%$ 가 설명되었다. 참여요인의 Cronbach's 
Table 2. Factor loading matrix and internal reliability.

\begin{tabular}{|c|c|c|c|c|}
\hline & 1 & 2 & 3 & 4 \\
\hline Factors & $\begin{array}{c}\text { Maintenance and } \\
\text { development of } \\
\text { professional } \\
\text { competencies }\end{array}$ & $\begin{array}{l}\text { Interaction and } \\
\text { responsibility of } \\
\text { professionals }\end{array}$ & $\begin{array}{c}\text { Job stability } \\
\text { and personal } \\
\text { profits }\end{array}$ & $\begin{array}{l}\text { Services for } \\
\text { customers }\end{array}$ \\
\hline To develop new professional knowledge and skills & 0.834 & 0.221 & 0.069 & 0.152 \\
\hline To maintain my abilities as an expert & 0.824 & 0.246 & 0.141 & 0.211 \\
\hline To determine my abilities as an expert in a more confident manner & 0.820 & 0.215 & 0.193 & 0.204 \\
\hline $\begin{array}{l}\text { Because it helps me to improve my responsibilities as an expert in } \\
\text { a more productive manner }\end{array}$ & 0.760 & 0.126 & 0.054 & 0.382 \\
\hline To keep up with new changes and improvements in my expert & 0.750 & 0.145 & 0.108 & 0.372 \\
\hline To enhance my performance even more than now & 0.744 & 0.178 & 0.114 & 0.319 \\
\hline $\begin{array}{l}\text { To fulfill knowledge and skills that would require for my activities } \\
\text { as a dietitian }\end{array}$ & 0.721 & 0.157 & 0.146 & 0.385 \\
\hline To determine my expert responsibilities in the future & 0.707 & 0.372 & 0.250 & 0.116 \\
\hline To improve the satisfaction level in what I do & 0.625 & 0.264 & 0.195 & 0.302 \\
\hline For changes in my expert responsibilities at this moment & 0.616 & 0.511 & 0.150 & 0.080 \\
\hline To increase performance efficiency & 0.605 & 0.288 & 0.243 & 0.436 \\
\hline To maintain my current competencies as they are now & 0.593 & 0.191 & 0.167 & 0.381 \\
\hline To maintain my expert service quality & 0.586 & 0.367 & 0.182 & 0.426 \\
\hline To encourage myself to think on my own & 0.585 & 0.318 & 0.226 & 0.210 \\
\hline To review my responsibilities as an expert & 0.581 & 0.519 & 0.266 & 0.144 \\
\hline Because it helps me to enhance my leadership as an expert & 0.535 & 0.343 & 0.336 & 0.344 \\
\hline To improve my reputation as an expert & 0.470 & 0.417 & 0.413 & 0.166 \\
\hline To share ideas with expert colleagues & 0.156 & 0.793 & 0.221 & 0.332 \\
\hline To learn from other experts via interactions & 0.184 & 0.759 & 0.169 & 0.373 \\
\hline To have my ideas connected to those of my other expert colleagues & 0.163 & 0.742 & 0.367 & 0.182 \\
\hline To get inspired by ideas of expert colleagues & 0.199 & 0.711 & 0.164 & 0.329 \\
\hline To take good consideration of my values as an expert & 0.477 & 0.677 & 0.213 & 0.036 \\
\hline To consider limits of my roles as an expert & 0.484 & 0.615 & 0.206 & 0.005 \\
\hline To evaluate on-going directions of my career & 0.498 & 0.606 & 0.237 & 0.025 \\
\hline To improve my reputation as an expert & 0.274 & 0.548 & 0.543 & 0.091 \\
\hline To increase chances to earn a financial profit in person & 0.128 & 0.178 & 0.858 & 0.171 \\
\hline To improve my occupational stability & 0.280 & 0.203 & 0.774 & 0.210 \\
\hline To increase chances to distribute profits among families and friends & 0.180 & 0.170 & 0.765 & 0.203 \\
\hline To increase chances for a promotion & 0.027 & 0.331 & 0.745 & 0.067 \\
\hline To satisfy needs of customers & 0.417 & 0.236 & 0.309 & 0.708 \\
\hline To accept needs of customers in a more efficient manner & 0.504 & 0.170 & 0.191 & 0.667 \\
\hline To enhance skills to deal with customers & 0.394 & 0.250 & 0.291 & 0.649 \\
\hline To enhance skills to deal with customers & 0.505 & 0.275 & 0.175 & 0.647 \\
\hline To improve my professional service ability to deal with customers & 0.569 & 0.230 & 0.141 & 0.589 \\
\hline Characteristic value & 9.977 & 5.884 & 4.179 & 4.137 \\
\hline Variance explanation (\%) & 29.343 & 17.307 & 12.290 & 12.168 \\
\hline Accumulation explanation (\%) & 29.343 & 46.650 & 58.940 & 71.108 \\
\hline Cronbach's $\alpha$ & 0.967 & 0.927 & 0.878 & 0.937 \\
\hline
\end{tabular}


$\alpha$ 값은 요인 1 이 0.967, 요인 2가 0.927 , 요인 3 이 0.878 , 요인 4 가 0.937 로 분석되어 모두 0.6 이상으로 나타나 신뢰할 수 있는 수준인 것으로 나타났다.

\section{3. 일반적 특성에 따른 전문영양사 계속교육의 참여동기}

대상자의 일반적 특성에 따른 전문영양사 계속교 육 참여동기에 대한 분석 결과는 Table 3 과 같다. 분석 결과 연령이 적을수록 '직업의 안정성, 개인의
이익'에 대한 이유가 높은 것으로 나타났으며 $(\mathrm{P}<$ $0.05)$, 최종학력에 따라서는 전문대학 졸업이나 4 년 제 대학 졸업의 경우 석·박사에 비해 상대적으로 '직업의 안정성, 개인의 이익'에 대한 이유가 높은 것으로 나타났다 $(\mathrm{P}<0.05)$. 근무처에 따라서는 유치 원, 어린이집, 기타 근무자의 경우 병원, 학교, 산업 체 근무자에 비해 상대적으로 '직업의 안정성, 개인 의 이익'에 대한 이유가 높은 것으로 나타났으며(P $<0.01)$, 영양사 업무 근무경력에 따라서는 6년 이하

Table 3. The participation reasons of continuing education according to the general characteristics.

\begin{tabular}{|c|c|c|c|c|c|c|}
\hline \multirow[b]{2}{*}{ Variables } & \multirow[b]{2}{*}{ PCA } & \multicolumn{4}{|c|}{ Participation reasons of continuing education of professional dietitians } & \multirow[b]{2}{*}{ Total } \\
\hline & & $\begin{array}{c}\text { Maintenance and } \\
\text { development of } \\
\text { professional } \\
\text { competencies }\end{array}$ & $\begin{array}{l}\text { Interaction and } \\
\text { responsibility of } \\
\text { professionals }\end{array}$ & $\begin{array}{l}\text { Job stability and } \\
\text { personal profits }\end{array}$ & $\begin{array}{l}\text { Services for } \\
\text { customers }\end{array}$ & \\
\hline \multirow{5}{*}{ Age } & $\leq 29$ & $5.60 \pm 1.190^{1)}$ & $5.13 \pm 1.184$ & $4.83 \pm 1.381^{\mathrm{c}}$ & $5.25 \pm 1.245$ & $5.34 \pm 1.119$ \\
\hline & $30 \sim 49$ & $5.77 \pm 0.979$ & $5.24 \pm 1.180$ & $4.60 \pm 1.460^{\mathrm{bc}}$ & $5.47 \pm 1.180$ & $5.44 \pm 1.013$ \\
\hline & $40 \sim 49$ & $5.93 \pm 0.848$ & $5.17 \pm 1.194$ & $4.29 \pm 1.347^{\mathrm{ab}}$ & $5.65 \pm 1.063$ & $5.49 \pm 0.868$ \\
\hline & $\geq 50$ & $5.65 \pm 1.144$ & $4.85 \pm 1.400$ & $4.07 \pm 1.409^{\mathrm{a}}$ & $5.57 \pm 1.416$ & $5.24 \pm 1.172$ \\
\hline & F-value $(\mathrm{P})$ & n.s & n.s & $3.186 *(0.024)$ & n.s & n.s \\
\hline \multirow{5}{*}{$\begin{array}{l}\text { The highest level of } \\
\text { education }\end{array}$} & College graduation & $5.69 \pm 1.372$ & $5.05 \pm 1.442$ & $4.65 \pm 1.652^{\mathrm{b}}$ & $5.40 \pm 1.376$ & $5.36 \pm 1.304$ \\
\hline & University graduation & $5.80 \pm 0.980$ & $5.24 \pm 1.211$ & $4.66 \pm 1.376^{b}$ & $5.56 \pm 1.159$ & $5.48 \pm 0.987$ \\
\hline & Master degree & $5.81 \pm 0.850$ & $5.10 \pm 1.131$ & $4.18 \pm 1.372^{\mathrm{a}}$ & $5.50 \pm 1.133$ & $5.38 \pm 0.892$ \\
\hline & Doctoral degree & $5.91 \pm 0.699$ & $5.31 \pm 0.863$ & $4.38 \pm 0.963^{\mathrm{ab}}$ & $5.33 \pm 0.996$ & $5.48 \pm 0.710$ \\
\hline & F-value $(\mathrm{P})$ & n.s & n.s & $3.057 *(0.028)$ & n.s & n.s \\
\hline \multirow{6}{*}{ Workplace } & Hospitals & $5.74 \pm 0.974$ & $5.15 \pm 1.153$ & $4.47 \pm 1.394^{\mathrm{a}}$ & $5.48 \pm 1.128$ & $5.39 \pm 0.966$ \\
\hline & Schools & $5.86 \pm 0.881$ & $5.14 \pm 1.286$ & $4.08 \pm 1.482^{\mathrm{a}}$ & $5.53 \pm 1.137$ & $5.40 \pm 0.949$ \\
\hline & Industries & $5.54 \pm 1.270$ & $4.90 \pm 1.446$ & $4.32 \pm 1.383^{\mathrm{a}}$ & $5.10 \pm 1.499$ & $5.17 \pm 1.243$ \\
\hline & $\begin{array}{l}\text { Public health centers or } \\
\text { welfare facilities }\end{array}$ & $5.86 \pm 1.147$ & $5.19 \pm 1.317$ & $4.64 \pm 1.345^{\mathrm{ab}}$ & $5.70 \pm 1.304$ & $5.52 \pm 1.130$ \\
\hline & $\begin{array}{l}\text { Kindergartens, } \\
\text { child care center etc. }\end{array}$ & $6.00 \pm 0.845$ & $5.45 \pm 0.967$ & $5.19 \pm 1.220^{b}$ & $5.72 \pm 1.031$ & $5.73 \pm 0.827$ \\
\hline & F-value $(\mathrm{P})$ & n.s & n.s & $4.382 * *(0.002)$ & n.s & n.s \\
\hline \multirow{6}{*}{$\begin{array}{l}\text { Work experience in } \\
\text { dietetic area (years) }\end{array}$} & $<1$ & $5.87 \pm 1.148$ & $5.38 \pm 1.207$ & $4.98 \pm 1.409^{c}$ & $5.65 \pm 1.153$ & $5.60 \pm 1.098$ \\
\hline & $1 \sim 3$ & $5.57 \pm 1.070$ & $5.05 \pm 1.243$ & $4.71 \pm 1.377^{\mathrm{bc}}$ & $5.30 \pm 1.187$ & $5.30 \pm 1.049$ \\
\hline & $4 \sim 6$ & $5.85 \pm 0.956$ & $5.26 \pm 1.068$ & $4.80 \pm 1.411^{\mathrm{c}}$ & $5.55 \pm 1.199$ & $5.53 \pm 0.950$ \\
\hline & $7 \sim 10$ & $5.74 \pm 0.952$ & $5.04 \pm 1.273$ & $4.07 \pm 1.360^{\mathrm{a}}$ & $5.42 \pm 1.202$ & $5.30 \pm 0.979$ \\
\hline & $>10$ & $6.05 \pm 0.816$ & $5.30 \pm 1.163$ & $4.26 \pm 1.353^{\mathrm{ab}}$ & $5.83 \pm 1.016$ & $5.60 \pm 0.889$ \\
\hline & F-value (P) & n.s & n.s & $5.877 * * *(0.000)$ & n.s & n.s \\
\hline Total & & $5.79 \pm 0.988$ & $5.17 \pm 1.205$ & $4.48 \pm 1.415$ & $5.51 \pm 1.173$ & $5.43 \pm 0.993$ \\
\hline
\end{tabular}

${ }^{1)} \mathrm{M}($ Mean $) \pm \mathrm{SD}$ (Standard deviation), n.s: not significant $* \mathrm{P}<0.05, * * \mathrm{P}<0.01, * * * \mathrm{P}<0.001$

Significance as determined by ANOVA-test, Duncan: $\mathrm{a}<\mathrm{b}<\mathrm{c}$ 
의 경우 7년 이상에 비해 상대적으로 '직업의 안정 성, 개인의 이익'에 대한 이유가 높은 것으로 나타 났다 $(\mathrm{P}<0.001)$. 반면 전문역량 유지 및 개발, 상호교 류 및 전문가의 책임, 고객에 대한 서비스 문항에 대해서는 연령, 최종학력, 근무처, 영양사 업무 근무 경력에 따라서 유의적인 차이는 나타나지 않았다.

\section{고 찰}

본 연구는 영양사의 직무능력 향상을 위한 계속 교육의 참여동기를 파악하기 위해 요인 분석 및 참 여동기에 따른 일반적 특성을 분석하여 이를 토대 로 영양사의 직무능력 증진을 위한 교육프로그램 기획 및 개발의 기초자료로 활용하고자 실시되었다.

영양사의 계속교육 참여동기에 대한 요인분석을 통해 '전문역량 유지 및 개발', '상호교류 및 전문가 의 책임', '직업의 안정성, 개인의 이익', '고객에 대 한 서비스' 등 4 개의 요인이 추출되었으며, 이는 간 호사를 대상으로 참여동기 척도를 사용한 연구결과 와 일치하였다(Grotelueschen 1985; Han \& Lee 2010). 이 중 ‘전문역량 유지 및 개발’이 가장 높게 나타났 으며 '고객에 대한 서비스'가 가장 낮게 나타났다. 이는 간호사를 대상으로 참여동기 척도를 사용한 선행연구들에서도 '전문성 향상과 개발', '전문성', '전문성 개발과 동료 간의 상호작용' 등으로 나타나 본 연구와 유사한 결과를 보였다(Aucoin 1998; Cervero 2001). 이 결과는 전문직에서의 전문성이 현 사 회에서 인정을 받고 있으며, 개인적인 이익보다는 전문성을 유지하고 개발해야 함을 더욱 강하게 인 식하고 있음을 보여주는 결과라 사료된다. 또한 간 호사, 물리치료사, 내과의사 등의 보건전문직에서의 결과와 동일한 결과로 영양사의 전문역량을 유지시 킬 수 있는 교육이 요구된다. 따라서 향후 영양사의 직무능력 향상을 위한 계속교육 프로그램 개발 시 참여동기를 유발하기 위해서는 영양사의 전문성 강 조된 프로그램을 기획할 필요가 있을 것으로 보인다.
일반적 특성에 따라 계속교육의 참여동기는 '직 업의 안정성, 개인의 이익'에 대한 요인이 전반적으 로 가장 낮은 점수를 보였으나 유의한 차이를 보였 다. 연령이 낮을수록 $(\mathrm{P}<0.05)$, 학력이 낮을수록 $(\mathrm{P}<$ $0.05)$, 경력이 적을수록 $(\mathrm{P}<0.001)$ '직업의 안정성 및 개인의 이익'이 유의하게 높은 점수를 보이는 경향 을 보였으며, 근무처에 따라서는 유치원 및 어린이 집 등의 기타 시설에 종사하는 영양사, 보건쇠사회 복지시설에서 종사하는 영양사 순으로 직업의 안정 성 및 개인의 이익에 대한 점수가 높은 것으로 나 타났다. 이는 각자의 위치에서 영양사직을 맡고 있 으면서도 연령, 학력 및 경력이 낮아 영양사직에 대 한 고용이 불안정한 상태의 영양사들이 지속적인 교육을 통해 전문성을 쌓고 발전해 나아가기 위해 계속교육의 참여동기가 높은 것으로 판단된다. 영양 사들의 이 같은 결과는 10 년 이상의 실무 경력을 쌓은 간호사들의 계속교육의 참여동기가 더 높았던 간호사직의 경우와 상반된 결과를 보였는데(Barriball \& While 1996; Han \& Lee 2010) 이는 1개의 업장에 서 홀로 다수의 조리사를 관리하는 중간관리자의 역할을 맡고 있는 영양사와 달리 1 개의 병원에서 연령과 경력이 다양한 간호사들이 함께 생활하면서 오는 심리적 경쟁 관계의 발생 가능성 등의 차이에 서 기인하여 서로 상반된 결과가 나타난 것으로 보 여진다.

이에 영양사의 계속교육 촉진 및 프로그램 개발 에 있어서, 영양사들의 계속교육 참여동기 요인이 반영된 연령, 학력 및 경력의 특징을 고려한 전문성 을 증진시킬 수 있는 프로그램으로 다양화 하여야 할 것이다. 영양사는 산업체, 병원 및 보건소 뿐만 아니라 다른 보건직에 비해 비교적 다양한 분야에 서 활동하는 직종으로 각 분야의 특이성이 고려된 전문성 개발 교육이 필요할 것으로 사료된다. 특히 본 연구결과 젊고, 경력이 비교적 길지 않은 영양사 들은 계속교육에 대한 참여동기가 높은 것으로 보 이므로, 교육 프로그램 개발 시 다양한 활동영역에 서의 전문성이 고려된 계속교육 프로그램을 기획하 
여 운영하는 것이 필요하겠다.

본 연구는 영양사의 직무능력 향상을 위한 계속 교육의 참여동기의 요인을 분석한 연구로, 이는 지 금까지 국내에서 미비하게 다루어졌던 영양사의 계 속교육 참여동기를 분석한 점과 이를 토대로 계속 교육의 촉진과 프로그램 개발을 위한 기초 자료를 제시했다는 점에 의미를 둘 수 있다. 그러나 본 연 구는 응답자의 연령과 근무장소별로 일부 영양사의 의견만 반영된 연구이므로 향후 행해지는 연구는 폭넓은 영양사를 대상으로 참여동기에 대한 분석이 시도되어야 할 것으로 보인다. 이러한 연구들이 지 속적으로 진행된다면, 영양사의 계속교육 촉진과 더 불어 영양사 개인의 성장 및 다양한 사회에서 이바 지하는 영양사의 위상도 함께 높아질 것으로 사료 된다.

\section{요약 및 결론}

본 연구는 영양사 직무능력 향상을 위한 계속교 육의 참여동기를 분석하여 향후 영양사의 계속교육 프로그램 개발을 위한 기초자료로 사용하기 위해 실시되었다. 영양사 622 명을 대상으로 조사된 설문 분석 결과는 다음과 같다.

1. 본 연구에 참여한 영양사는 연령별, 최종학력별, 근무처별, 영양사 업무 근무경력별로 분류하여 조사하였다. 조사에 참여한 영양사의 연령대는 40 대가 262명(42.1\%)으로 가장 많았으며, 최종학력 은 4년제 대학졸업이 322 명 $(51.8 \%)$ 으로 가장 많 은 것으로 나타났다. 근무처는 학교 영양사가 251 명 $(40.4 \%)$ 으로 가장 많은 것으로 나타났으며, 근 무 경력은 7 10년 228명(36.7\%)이 가장 많은 것 으로 나타났다.

2. 전문영양사 계속교육 참여동기에 대한 타당성 및 신뢰도 검증을 위해 요인분석을 실시한 결과 총 4 개의 요인이 도출되었다. 이는 각각 '전문역량 유지 및 개발', ‘상호교류 및 전문가의 책임', ‘직
업의 안정성, 개인의 이익' '고객에 대한 서비스' 라 명명하였고, 이 중 '전문역량 유지 및 개발'의 설명분산이 $29.343 \%$ 로 가장 큰 것으로 나타났다. 참여요인의 Cronbach's $\alpha$ 값은 각각 $0.967,0.927$, $0.878,0.937$ 로 분석되었다.

3. 본 설문에 참여한 영양사의 일반적 특성에 따른 계속교육 참여동기에 대한 분석결과 연령이 낮을 수록, 학력이 낮을수록, 유치원, 어린이집, 기타 근무자일 경우, 6 년 이하의 경우에서 '직업의 안 정성, 개인의 이익'에 대한 참여동기가 높은 것으 로 분석되었다.

이상 결과를 종합하여 볼 때 영양사 계속교육 촉 진 및 프로그램 개발을 위해 본 연구에서 분석된 연령, 학력, 근무처 및 경력 등을 고려하여 전문성 을 증진시킬 수 있는 프로그램을 개발해야 할 것이 며, 특히 연령이 적고, 경력이 길지 않은 영양사의 참여동기가 높은 것으로 보아 이들을 위해 전문성 을 가진 프로그램 개발이 우선적으로 이루어져야 할 것으로 사료된다.

\section{참고문헌}

Aucoin JW (1998): Participation in continuing nursing education programs by staff development specialists. J Nurses Staff Dev 14(5):219-226

Barriball KL, While AE (1996): Participation in continuing professional education in nursing: findings of an interview study. J Adv Nurs 23(5):999-1007

Cervero RM (2001): Continuing professional education in transition, 1981-2000. Int J Lifelong Educ 20(1-2):16-30

DeSilets LD (1995): Assessing registered nurses' reasons for participating in continuing education. J Contin Educ Nurs 26(5):202-208

Grotelueschen AD (1985): Assessing professionals' reason for participation in continuing education. New Dir Contin Educ $27: 33-45$

Han SM, Lee HS (2010): Nurses' reasons for participation in 
continuing nursing education. J Voc Educ Res 29(2):189-204

Hayajneh F (2009): Attitudes of professional Jordanian nurses toward continuing education. J Contin Educ Nurs 40(1): 43-48

Kang YS (2004): A study on development of a continuing education program model in relation to gerontology and geri- atrics for nurse caring for the elderly. J Korean Acad Soc Nurs Edu 10(1):7-19

Murphy C, Cross C, McGuire D (2006): The motivation of nurses to participate in continuing professional education in Ireland. Journal of European Industrial Training 30(5):365384 